\title{
A SRY-HMG box frame shift mutation inherited from a mosaic father with a mild form of testicular dysgenesis syndrome in Turner syndrome patient
}

Mohammad Shahid ${ }^{1,3}$, Varinderpal S Dhillon ${ }^{2^{*}}$, Hesham Saleh Khalii ${ }^{3}$, Shameemul Haque ${ }^{4}$, Swaraj Batra ${ }^{5}$, Syed Akhtar Husain ${ }^{4}$, LHJ Looijenga ${ }^{6}$

\begin{abstract}
Background: Sex determining factor (SRY) located on the short arm of the $Y$ chromosome, plays an important role in initiating male sex determination, resulting in development of testicular tissue. Presence of the SRY gene in females results in $X Y$ sex reversal and increased risk of gonadal germ cell tumours if the karyotype also includes the so-called GonadoBlastoma on the Y chromosome (GBY) region. The majority of mutations within the SRY gene are de novo affecting only a single individual in the family. The mutations within the high-mobility group (HMG) region have the potential to affect its DNA binding activity.

Case Presentation: We performed G- and R-banding cytogenetic analysis of the patient and her family members including her father. We also performed molecular genetic analysis of SRY gene. Cytogenetic analysis in the patient (Turner Syndrome) revealed the mosaic karyotype as 45, X/46, XY (79\%/21\% respectively) while her father (milder features with testicular dysgenesis syndrome) has a normal male karyotype (46, XY). Using molecular approach, we screened the patient and her father for mutations in the SRY gene. Both patient and her father showed the same deletion of cytosine within HMG box resulting in frame shift mutation (L94fSX180), the father in a mosaic pattern. Histological examination of the gonads from the patient revealed the presence of gonadoblastoma formation, while the father presented with oligoasthenozoospermia and a testicular seminoma. The frameshift mutation at this codon is novel, and may result in a mutated SRY protein.
\end{abstract}

Conclusion: Our results suggest that lack of a second sex chromosome in majority cells of the patient may have triggered the short stature and primary infertility, and the mutated SRY protein may be associated with the development of gonadoblastoma. It is of importance to note that mosaic patients without a SRY mutation also have a risk for malignant germ cell tumors.

\section{Background}

Turner Syndrome (TS) is a relatively common chromosomal disorder, caused by complete or partial X monosomy in some or all cells [1]. Almost half of the cases have typical TS karyotype (45, X), whereas the remaining cases either have a derivative sex chromosome in the investigated cells or a mosaic karyotype, with the

\footnotetext{
* Correspondence: varinderpal.dhillon@csiro.au

${ }^{2}$ Commonwealth Scientific and Industrial Research Organisation (CSIRO) Food and Nutritional Sciences, Gate 13, Kintore Avenue, PO BOX 10041 Adelaide SA 5000, Australia

Full list of author information is available at the end of the article
}

second cell line having a normal or structurally rearranged sex chromosome. TS with different karyotypes have demonstrated the presence of a Y-chromosome or $\mathrm{Y}$ - derived material in frequencies ranging from 4-61\% $[2,3]$. TS with mosaic $45, \mathrm{X} / 46, \mathrm{XY}$ karyotype comprises a phenotype spectrum of female (10-15\%) having mutated SRY and an increased risk for developing of gonadoblastoma or dysgerminoma [4]. SRY is proven to direct sex-determination pathway towards male development $[5,6]$. This single exon gene is located on distal part of the short arm of Y-chromosome spanning $3.8 \mathrm{~kb}$ and encodes a 204 amino acid protein. SRY contains a 
DNA-binding domain high-mobility group (HMG) motif in the middle of the protein [5,7]. The presence of DNA-binding domain in SRY protein suggests its regulatory role and it could work as a transcription factor. Inactivating mutations in $S R Y$ gene cause failure to develop testis and has been found to account for approximately $15 \%$ of cases with gonadal dysgenesis and $\mathrm{XY}$ sex-reversal $[8,9]$. However, a majority of these patients may have mutations in other genes involved in sex determination and differentiation (in term for development of phenotypical sex characteristics) pathway or in the regulatory elements of the $S R Y$ gene. To the best of our knowledge more than 60 mutations have been identified within open reading frame (ORF) of the $S R Y$ gene, and majority of these are located within HMG box, thus highlighting the vital and significant role of this domain [10-12]. Less than 20 familial mutations in $S R Y$ gene have been reported so for in the literature. Here, we report a new point mutation in TS patient who inherited the mutation from a phenotypically normal father. However, this male showed a form of Testicular Dysgenesis Syndrome, i.e., oligoasthenozoospermia and a testicular seminoma. To the best of our knowledge no mutations at the above mentioned evolutionary conserved codon have been reported previously in the literature.

\section{Case Presentation}

Informed consent was obtained from the patient, her family members and control individuals who participated in the present study. This study was approved by the ethics as well as bio-safety committee of the hospital and university.

\section{Patient II-5}

Patient II-5, a 23 years old female, with short stature, ambiguous external genitalia and absence of pubertal development was referred for cytogenetic analysis. Physical examination revealed her height as $145 \mathrm{~cm}$ (below the fifth percentile). This patient showed multiple Turner stigmata such as micrognathia, low-set ears, high-arched palate, short and webbed neck, bilateral cubitus valgus, low hair line, presence of Müllerian structure, widely spaced nipples, nail dysplasia and multiple nevi. Sparse axillary and pubic hairs (Tanner stage II) were observed, and there was no clitoromegaly. Endocrinological studies demonstrated hypergonadotropic hypogonadism (estradiol $12 \mathrm{pg} / \mathrm{ml}$; LH $26.2 \mathrm{mIU} / \mathrm{ml}$; FSH $50.2 \mathrm{mIU} / \mathrm{ml}$ ) as well as normal female concentrations of testosterone and androstenedione. Sonographic examination revealed a normal-sized uterus with a thin endometrium and bilateral Müllerian derivatives. Ovaries were not visible, but thickened structures resembling streak gonads were present. Histological investigations revealed only fibrous stromal tissue. Gonadoblastoma was found in the streak gonads. Standard cytogenetic analysis was performed and showed mosaic $45, \mathrm{X} / 46$, $\mathrm{XY}$ karyotype.

\section{Patient I-1}

He is the father of patient II-5 (Fig. 1). At the age of 53 $\mathrm{yr}$, his height and weight were $1.79 \mathrm{~m}$ and $84 \mathrm{~kg}$ respectively. The patient had normal secondary sex characteristics. Orchidectomy was performed at the age of $48 \mathrm{yr}$ for the presence of pure testicular seminomatous tumor. Histological examination of the gonad did not present any signs of dysgenesis. At the time of examination, his plasma testosterone $(4.1 \mathrm{ng} / \mathrm{ml}$; normal $2.5-9.5)$ and $\mathrm{LH}$ (3.9 mU/ml; normal 2.2-5.8) and FSH levels $(7.1 \mathrm{mU} / \mathrm{ml}$; normal 2-10) were within the normal range of an adult male. Semen analysis showed signs of oligoasthenozoospermia (volume $1.4 \mathrm{ml}$; semen concentration $7.4 \times 10^{6} /$ $\mathrm{ml}$; normal $20-40 \times 10^{6} / \mathrm{ml} ; 37 \%$ motile sperm after $1 \mathrm{~h})$. Reduced semen quantity and presence of testicular cancer classifies him as the one with milder form of testicular dysgenesis syndrome.

\section{Cytogenetic and Molecular analysis}

Both G- and R-banding was performed on metaphase spreads from peripheral blood of the patient, her siblings and parents. Genomic DNA was extracted from peripheral blood as well as gonadal tissue using DNA isolation kit following manufacturers' instructions. SRY polymerase chain reaction amplifications, single strand conformational polymorphism and sequencing were performed as reported elsewhere [13]. The resulting PCR products from I-1, II-5 were cloned and then 10 clones were sequenced. In present study, cytogenetic analysis has been done using G- and R-banding technique. The patient (II-5) had a karyotype $45, \mathrm{X} / 46, \mathrm{XY}$ (the ratio being $79 \%$ and $21 \%$ respectively) and her father (I-1) a normal male karyotype (46, XY, 100\%). Patient II-5 showed altered level of estradiol, LH, FSH but with normal female concentration of testosterone and androstenedione. Both patient and her father showed altered migration of PCR products in the SSCP assay (Fig 1A). Both direct sequencing and sequencing from cloning revealed a point mutation in HMG box of SRY gene in the patient (Fig 1B). The sequence has a deletion of $\mathrm{C}$ (cytosine) leading to frame shift mutation within the open reading frame inside the highly conserved DNAbinding motif-HMG box leading to a premature stop codon. The mutation is described as L94fs X180. Sequencing of both PCR products and cloning products confirmed the presence of the same mutation as seen in his daughter (II-5) however, the mutation is mosaic in nature. It is clear from the pedigree as well that gonadal mosaicism exits as indicated by the affected daughter 
$(A)$

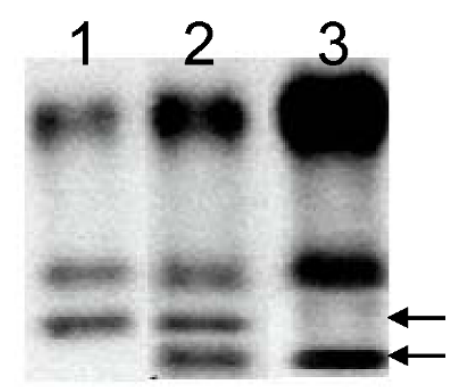

(B)

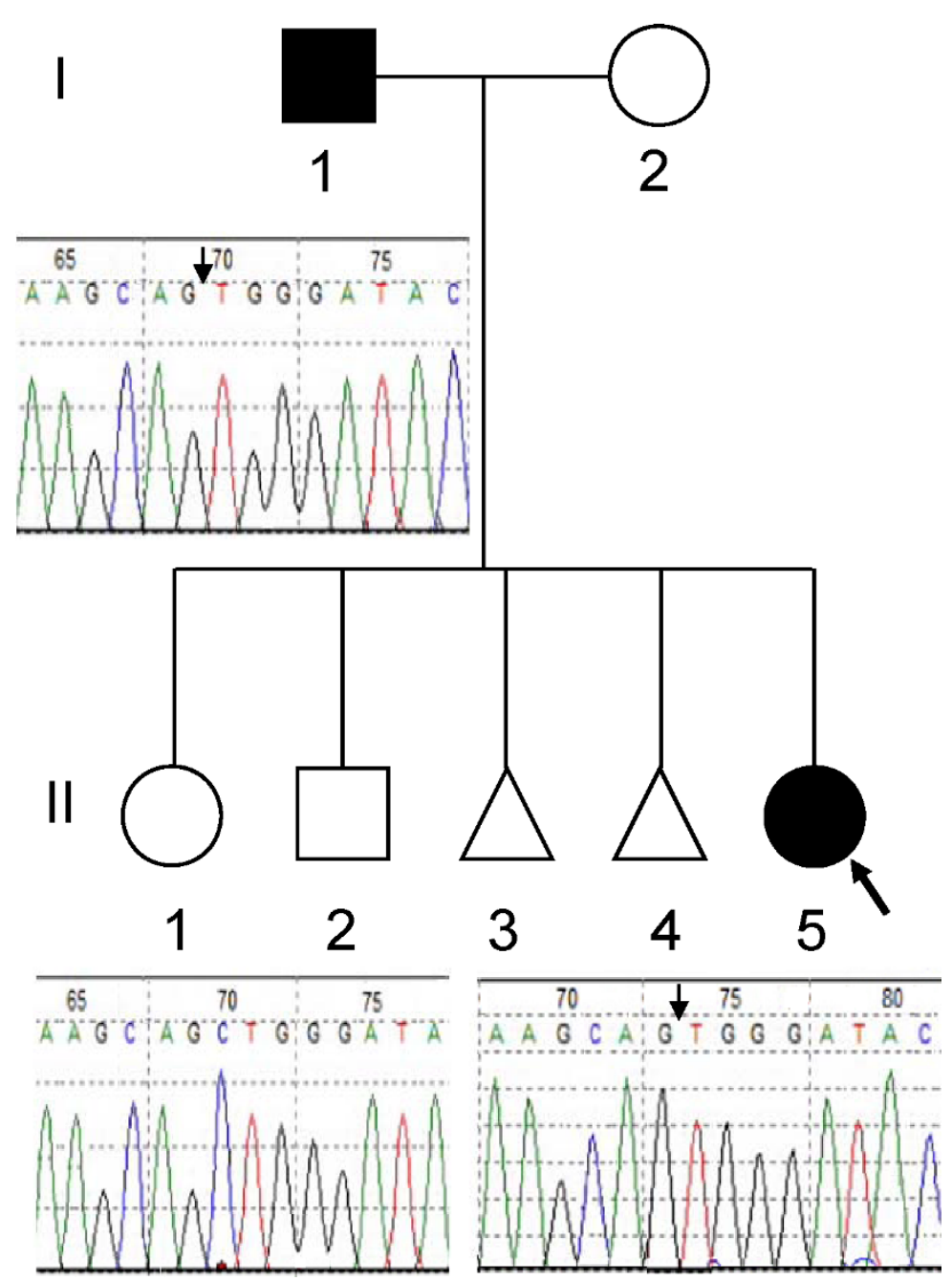

Figure 1 Mutation(s) in the SRY gene in the affected family. (A) Polymerase chain reaction-SSCP analysis of SRY gene. Lane 1, SRY from normal male control DNA (II-2); lanes 2 and 3: SRY with altered band from patient I-1 and II-5 respectively. The migration pattern from I-1 clearly indicates that there are two different alleles that he shares with normal son (not shown) and affected daughter; (B) Pedigree of the affected family also showing partial electropherograms of the mutation (deletion of $\mathrm{C}$ in the HMG box (helix 2) leading to a premature stop codon as L94fSX180) identified in patient II-5 and her father (I-1). These results were obtained by sequencing of the amplification products after cloning. Wild-type electropherogram identified in the normal brother (II-2) is also indicated. White symbols denote unaffected individuals where as black symbols denote affected individuals. The arrow indicates the proband (II-5).

and the normal son, which were genetically proven to be the biological children of the father.

Normal male sex determination in mammals is targeted by the $S R Y$ gene present on Y chromosome. Its timing and expression is exquisitely regulated and must probably reach the required threshold for testis formation in the developing embryo [10]. The patient reported here have a mosaic $45, \mathrm{X} / 46, \mathrm{XY}$ karyotype with multiple Turner stigmata. We identified a new $S R Y$ mutation in this patient. This mutation, leading to a premature stop, may result in altered non-functional protein as evident by the inability to develop male sex organs. Sex determination during early embryonic stages is characterized by complex interaction of various genetic and non-genetic factors [14]. There is significant evidence that $S R Y$ is essential for sex determination [5]. However, there are examples of $S R Y$-negative individuals who differentiate to males (20\% XX males). Mutations in $S R Y$ gene and presence of the dominant $45, \mathrm{X}$ cell line in the patient may have acted in a cumulative 
manner to induce a cause-effect relationship. This may account for non-masculinization in an otherwise originally XY embryo. Unequal distribution of two cell lines as seen in this patient may have originated at the time of implantation and their distribution into fetal and placental poles [15]. SRY protein belongs to the SOX family of transcription factors characterized by HMG domain having DNA binding and bending properties. It has the ability to mediate protein-protein interactions and contain signals for its nuclear import [16,17]. This mutational change as reported here in this report may have an electrostatic and hydrophobic interaction with phosphate and sugars, respectively, of the DNA backbone. This alteration can result in specific orientation and binding DNA bases in the major groove which can thus totally or at least partially inhibit or reduce its (SRY) interactions with DNA [18]. Deletion of cytosine at codon 94 which is evolutionary conserved (Fig. 2) in mammals has resulted in a nonsense frame shift mutation (L94fsX180) within the HMG box, resulting in an altered protein at the $C$ terminus end. A phenotypical female with mosaic $45, \mathrm{X} / 47, \mathrm{XYY}$ karyotype and a frame-shift mutation at codon 4 of $S R Y$ gene has been reported in the literature [19]. It has been shown that the mutant $S R Y$ may be assumed to induce a non-functional SRY-coded protein that lacks DNA-binding motif. Similarly there is another report that describes two patients with 45, X/46, XY (mosaic karyotype) have a missense mutation as $\mathrm{S} 18 \mathrm{~N}$ in the $5^{\prime}$ non-HMG box region in blood as well as in streak gonads [20]. Mutations in $S R Y$ gene are among known causes of $46, \mathrm{XY}$ pure gonadal dysgenesis (PGD). It has been generally accepted that mutations in HMG box disrupt the gene's function. Likewise, mutations outside HMG box have been reported in several patients with PGD, and one has been detected in a 46, XY female with partial ovarian function [20-22]. We analyzed DNA from her father and found the similar mutation but in the mosaic condition in peripheral blood as well as in sperm DNA. Transmission of this mutation from father to the affected daughter and a wild type $S R Y$ sequence to the normal son further provide the basis that this mutation is present in the mosaic condition in father. The mutation has resulted in a truncated SRY protein and hence, could have altered its binding activity. The development of normal male sex determination and differentiation might be due to the presence of a transcript with wild type SRY protein due to the mosaicism in the gonadal tissue. It is quite possible that some mutational event(s) might have occurred during the early embryonic life. Our findings are further strengthened by other reports of transmission of mutation from fertile fathers to their $\mathrm{XY}$ daughters $[14,23,24]$. In the present study, the patient also developed a bilateral gonadoblastoma, a

$\begin{array}{lll}58 & 94 & 137 \\ \text { ISSRY } & \text { DRVKRPMIIAFIVWSRD QRR KMALE IIPRMR IISEISKQLGY QWKMLTEAEKWPFFQE AQKLQAMHREKYPIIYKYRPRRKAK }\end{array}$

mSRY GH VKRPMIAFMUWSRGERHKLAQQIIPDMQIITEISKQLGCFWKSLTEAEKRP FF QEAQRLK ILHREKYPIYKKYQPHRRAKV

CSRY DRVKRPMIAFFWWSRD QRRKMALE IIPRMRIISEISKQLGYOWKMLTE AEKWPFFOEAOKLQAMHREK YPIIYKYRPRRKAII

DCSRY DRVKRPMHIAFFWWSRDQRRKMALEIIPRMRIISEISKQLGYOWKMLTAAEKWPFFQEAQKLQAMHR EKYPIIYKYRPRRKAII

¡SRY DRVKRPMIIAFIUWSRD QRRKMALE IIPRMRIISEISKQLGYOWKMLTEAEKWPFFQE AQKLQAMHREKYPIIYKYRPRRKAK

DYSRY DRVKRPMIIAFIUWSRD QRRKMALEIIPKMRIISEISKQLGYQWKMLTEAEKWPFFQEAQKLQAMHREKYPIIYKYRPRRKAK

IISRY DRVKRPMIIAFIVWSRD QRRKMALEIIPKMRIISEISKQLGYRWKMLTEAEKWPFFOEAQKLQAMHREKYPIYKK YRPRRKAK

ISSRY DRVKRPMIIAFIVWSRD QRRKMALEIPKMMRIISEISKQLGYQWKMLTEADKWPFFQEAQKLQAMHREKYPIIYKYRPRRKAK

cjSRY IIRVKRPIMIAFIVWSRDQRRKMAVEHIPDMRIISE ISKRLGYQWKLLTEAEKWPFFQEAQKLQAMHREKYPIIYKYRPRRKAII

\section{Helix 1 Helix 2}

Figure 2 Alignment of HMG box sequences of SRY proteins from different mammalian species. Position 94 (shown in red) is highly conserved in different species (h: human; m: mouse; c: Chimpanzee; pc: Pygmy Chimpanzee; g: gorilla; py: Pongo; hl: Hylobates; b: Baboon and cj: (alitrix). 
precursor lesion for malignant germ cell tumors in the dysgenetic gonad is further supported by previous studies [25-29].

It is widely recognized that dysgenetic gonads, in some cases related to $S R Y$ mutations develop gonadoblastoma only in case GBY region is present in the genome. However, the molecular cause of gonadoblastoma formation remains elusive. The failure of indifferent gonads to develop during embryogenesis into testes ultimately leads to a phenotypical female with delayed puberty and amenorrhea. The GBY locus on Yq region is thought to contain a proto-oncogene involved in the origin of these tumors [30], for which TSPY is one of the likely candidates, supported by strong expression of TSPY in CIS and GB [31]. Normally, TSPY is expressed in spermatogonia of the adult testis and is believed to be related to mitotic proliferation [32]. The presence of streak gonads may be attributed to the invasion of primary genital ridge by the 45 , X cell line during early developmental stages. Pubertal virilization in some TS patients represents an alarming sign of undetected Y-chromosome positive cell lines that increase risk for developing gonadoblastoma [19]. The mosaicism with Y-bearing cell line (though with defective/mutated SRY) even at low levels formed during paternal meiosis and maternal non-disjunction during meiotic process may explain the mechanisms underlying the abnormal sex development. This is the second report that describes the mosaic fertile father who shows milder features associated with testicular dysgenesis syndrome and third report that describes the patients with sex development disorders (DSD) having mosaic mutation in $S R Y$ gene $[24,33]$. The risk for the development of germ cell tumors is an important factor to deal with the management of patients having sex development disorders (DSD) [34]. To our knowledge this is the first report that describes the $S R Y$ mutation in father who also shows oligoasthenozoospermia and has developed testicular seminoma. Both oligoasthenozoospermia and testicular cancer comprises the milder form of underlying entity associated with Testicular Dysgenesis syndrome (TDS) which can be caused by genetic and/or environmental factors. However, till date no specific causes of this entity have been identified. It may be possible that insufficient androgen production during the fetal testis developmental stages may be associated with downstream entities like TDS. It may be noted that the grand father (deceased) of this patient (II-1) was associated with the pesticide industry for quite a long time before the birth of patient I-1. Therefore, it is possible that this environmental exposure may also be responsible to certain extent for this condition in I-1 that is inherited by the patient II-5. The present and the previous published paper [24] strengthens the role various genetic factors along with the underlying mutations in $S R Y$ gene play in abnormal sex development disorders, related to malignant transformation of germ cells.

\section{Conclusion}

The present finding, especially the frameshift mutation in the highly conserved codon in the HMG box of $S R Y$ gene, further strengthen the functional importance of this gene in the sex development. To the best of our knowledge this is the first case (I-1) with the variant form of TDS phenotype having mosaic mutation in SRY gene. The frameshift mutation has been inherited by the daughter (II-5). It is therefore, concluded that TS patients must be analysed both by conventional cytogenetic and molecular genetics approaches to rule out the presence of the Y chromosome and/or the $S R Y$ gene, as well as the GBY region.

\section{Acknowledgements}

We thank the patient, her family members and other study participants for their co-operations in conducting this study. We also thank the other clinicians and staff members from the Department of Obstetrics and Gynaecology, and Male Family Welfare Centre, Maulana Azad Medical College and Lok Nayak and Associated Hospitals, New Delhi, India.

\section{Author details}

${ }^{1}$ College of Dentistry, Alkharj University, Alkharj, Kingdom of Saudi Arabia. ${ }^{2}$ Commonwealth Scientific and Industrial Research Organisation (CSIRO) Food and Nutritional Sciences, Gate 13, Kintore Avenue, PO BOX 10041 Adelaide SA 5000, Australia. ${ }^{3}$ College of Dentistry, King Saud University, Riyadh, Kingdom of Saudi Arabia. ${ }^{4}$ Department of Biosciences, Jamia Millia Islamia (A Central University), Jamia Nagar, New Delhi 110025, India.

${ }^{5}$ Department of Obstetrics and Gynecology, Lok Nayak Jai Prakesh Hospital and Associates, Maulana Azad Medical College Campus, Bhadur Shah Zafar Marg, New Delhi 110002, India. 'Department of Pathology, Erasmus MC University Medical Center Rotterdam, Daniel den Hoed Cancer Center, Rotterdam, The Netherlands.

\section{Authors' contributions}

VSD and SAH participated in the conception and the design of the study, MS conducted the molecular analyses, SH performed cytogenetic analysis, HSK performed endocrinological analysis and SB clinically diagnosed the family. VSD and LHJL have written the manuscript while others helped in further revising the manuscript. All authors read and approved the final manuscript.

\section{Competing interests}

The authors declare that they have no competing interests.

Received: 23 February 2010 Accepted: 19 September 2010 Published: 19 September 2010

\section{References}

1. Gimelli G, Gimelli S, Dimasi N, Bocciardi R, Di Battista E, Pramparo T, Zuffardi O: Identification and molecular modelling of a novel familial mutation in the SRY gene implicated in the pure gonadal dysgenesis. Eur J Hum Genet 2007, 15:76-80.

2. Lopez M, Canto P, Aguinaga M: Frequency of $Y$ chromosomal material in Mexican patients with Ullrich-Turner syndrome. Am J Med Genet 1998, 76:120-124.

3. Patsalis PC, Sismani C, Hadjimarcou Ml: Detection and incidence of cryptic Y chromosome sequences in Turner syndrome patients. Clin Genet 1998, 53:249-257. 
4. Scully RE: Gonadoblastoma: a review of 74 cases. Cancer 1970 25:1340-1356.

5. Sinclair AH, Beerta P, Palmer MS, Hawkins JR, Griffiths BL, Goodfellow PN, Fellous $\mathrm{M}$ : A gene from the human sex-determining region encodes a protein with homology to a conserved DNA-binding motif. Nature 1990 346:240-244

6. Brennan J, Capel B: One tissue, two fates: molecular genetic events that underlie testis versus ovary development. Nat Rev Genet 2004, 5:509-521.

7. Koopman P, Gubbay J, Vivian N, Goodfellow P, Lovell-Badge R: Male development of chromosomally female mice transgenic for Sry. Nature 1991, 351:117-21.

8. Harley VR, Jackson DI, Hextall PJ, Hawkins JR, Berkovitz GD, Sockanathan S, Lovell-Badge R, Goodfellow PN: DNA binding activity of recombinant SRY from normal males and XY females. Science 1992, 255:453-456.

9. Behlke MA, Began JS, Page DC: Evidence that the SRY protein encoded by a single exon on the human Y-chromosome. Genomics 1993, 17:736-739.

10. Cameron FJ, Sinclair AH: Mutations in SRY, SOX9: testis determining gene. Human Mutat 1997, 9:388-395.

11. Margarit E, Soler A, Carrio A, Oliva R, Costa D, Vendrell T, Rosell J, Ballesta F: Molecular, cytogenetic and clinical characterization of six XX males including one prenatal diagnosis. J Med Genet 1998, 35:727-730.

12. Assumpcao JG, Benedetti CE, Maciel-Guerra AT, Guerra G, Baptista MTM, Scolfaro MR, de Mello MP: Novel mutations affecting SRY DNA-binding activity: the HMG box $\mathrm{N} 65 \mathrm{H}$ associated with $46, \mathrm{XY}$ pure gonadal dysgenesis and the familial non-HMG box R30l associated with variable phenotype. J Mol Med 2002, 80:782-790.

13. Shahid M, Dhillon VS, Jain N, Hedau S, Diwakar S, Sachdeva P, Batra S, Das BC, Husain SA: Two new novel point mutations localized upstream and downstream of the HMG box region of the SRY gene in three Indian 46, XY females with sex reversal and gonadal tumour formation. Mol Hum Reprod 2004, 10:521-526.

14. McElreavey K, Fellous M: Sex determination and the $\mathrm{Y}$ chromosome. Am J Med Genet 1999, 89:176-185.

15. Pontiggia A, Rimini R, Harley VR, Goodfellow PN, Lovell-Badge R, Bianchi ME: Sex-reversing mutations affect the architecture of SRY-DNA complexes. EMBO J 1994, 13:6115-6124.

16. Sudbeck $P$, Scherer G: Two independent nuclear localization signals are present in the DNA-binding high-mobility group domains of SRY and SOX9. J Biol Chem 1997, 272:27848-27852.

17. Wilson M, Koopman P: Matching SOX: partner proteins and cofactors of the SOX family of transcriptional regulators. Curr Opin Genet Dev 2002, 12:441-446.

18. Werner MH, Bianchi ME, Gronenborn AM, Clore GM: NMR spectroscopic analysis of the DNA conformation induced by the human testis determining factor SRY. Biochemistry 1995, 34:11998-12004.

19. Takagi A, Imai A, Tamaya T: A novel sex-determining region on $Y$ (SRY) nonsense mutation identified in a 45, X/47, XYY female. Fertil Steril 1999, 72:167-169.

20. Canto P, De La Chesnaye E, Lopez M, Cervantes A, Chavez B, Vilchis F, Reyes E, Ulloa-Auirre A, Kofman-Alfaro S, Mendez JP: A mutation in the $5^{\prime}$ non-high mobility group box region of the $S R Y$ gene in patients with Turner syndrome and Y mosaicism. J Clin Endocrinol Metab 2000, 85:1908-1911.

21. Fernandez R, Marchal JA, Sanchez A, Pasaro E: A point mutation, R59G, within HMG-SRY box in a female $45, \mathrm{X} / 46, \mathrm{X}$, psu $\operatorname{dic}(\mathrm{Y})(\mathrm{pter} \rightarrow \mathrm{q} 11$ : q11 $\rightarrow$ pter). Hum Genet 2002, 111:242-246.

22. Shahid M, Dhillon VS, Aslam M, Husain SA: Three new novel point mutations localized within and downstream of High-Mobility Group-box region in SRY gene in three Indian females with Turner syndrome. J Clin Endocrinol Metab 2005, 90:2429-2435.

23. McElreavey K, Vilain E, Abbas N, Costa JM, Souleyreau N, Kucheria K, Boucekkine $\mathrm{C}$, Thibaud $\mathrm{E}$, Brauner $\mathrm{R}$, Flamant $\mathrm{F}$ : $\mathrm{XY}$ sex reversal associated with deletion 50 to the $S R Y$ HMG-box in the testis determining region. Proc Natl Acad Sci USA 1992, 89:11016-11020.

24. Isidor B, capito C, Paris F, Baron S, Corradini N, Cabaret B, Leclair M-D, Giraud M, Martin-Coignard D, David A, Sultan C, Le Caignec C: Familial frame shift SRY mutation inherited from a mosaic father with testicular dysgenesis syndrome. J Clin Endocrin Metab 2009, 94:3467-3471.
25. Manuel M, Katayama KP, Jones HW: The age of occurrence of gonadal tumors in intersexes patients with a Y chromosome. Am J Obstet Gynecol 1976, 124:293-300.

26. Schmitt-Ney M, Thiele $H$, Kaltwaber $P$, Bardoni B, Cisternino M, Scherer G: Two novel SRY missense mutation reducing DNA binding identified in XY females and their mosaic father. Am J Hum Genet 1993, 56:862-869.

27. Tajima T, Nakae J, Shinohara N, Fujieda K: A novel mutation localized in the $3^{\prime}$ non-HMG box region of the $S R Y$ gene in $46, X Y$ gonadal dysgenesis. Hum Mol Genet 1994, 3:1187-1189.

28. Uehara S, Funato T, Yaegashi N, Suzuki H, Sato J, Sasaki T, Yajima A: SRY mutation and tumor formation on the gonads of $X Y$ pure gonadal dysgenesis patients. Cancer Genet Cytogenet 1999, 113:78-84.

29. Uehera S, Hashiyada M, Sato K, Nata M, Funato T, Okamura K: Complete XY gonadal dysgenesis and aspects of the $S R Y$ genotype and gonadal tumor formation. J Hum Genet 2002, 47:279-284.

30. Page DC: Hypothesis: a Y chromosomal gene causes gonadoblastoma in dysgenetic gonads. Development 1987, 101:151-155.

31. Kersemaekers AM, Honecker F, Stoop H, Cools M, Molier M, Wolffenbuttel K Bokemeyer C, Li Y, Lau YF, Oosterhuis JW, Looijenga LH: Identification of germ cells at risk for neoplastic transformation in gonadoblastoma: an immunohistochemical study for OCT3/4 and TSPY. Hum Pathol 2005, 36:512-521.

32. Lau YF: Gonadoblastoma, testicular and prostate cancers, and the TSPY gene. Am J Hum Genet 1999, 64:921-927.

33. Braun A, Kammerer S, Cleve H, Löhrs U, Schwarz HP, Kuhnle U: True hermaphroditism in a $46, X Y$ individual, caused by a postzygotic somatic point mutation in the male gonadal sex determining locus (SRY): molecular genetics and histological findings in a sporadic case. Am J Hum Genet 1993, 52:578-85.

34. Cools M, Drop SL, Wolffenbuttel KP, Oosterhuis JW, Looijenga LH: Germ cell tumors in the intersex gonad: old paths, new directions, moving frontiers. Endocr Rev 2006, 27:468-84.

\section{Pre-publication history}

The pre-publication history for this paper can be accessed here: http://www.biomedcentral.com/1471-2350/11/131/prepub

doi:10.1186/1471-2350-11-131

Cite this article as: Shahid et al: A SRY-HMG box frame shift mutation inherited from a mosaic father with a mild form of testicular dysgenesis syndrome in Turner syndrome patient. BMC Medical Genetics 2010 11:131.

\section{Submit your next manuscript to BioMed Central and take full advantage of:}

- Convenient online submission

- Thorough peer review

- No space constraints or color figure charges

- Immediate publication on acceptance

- Inclusion in PubMed, CAS, Scopus and Google Scholar

- Research which is freely available for redistribution

Submit your manuscript at www.biomedcentral.com/submit
Biomed Central 